\title{
Percepções de beneficiários sobre a efetividade do Programa Minha Casa Minha Vida
}

\author{
Perceptions of beneficiaries about the effectiveness of Minha Casa \\ Minha Vida Program
}

http://dx.doi.org/10.5007/2178-4582.2015v49n1p145

Vitor Matheus Oliveira de Menezes

Universidade Federal da Bahia, Salvador/BA, Brasi

\begin{abstract}
Este artigo visa analisar as percepções dos beneficiários do Programa Minha Casa Minha Vida sobre a efetividade da política pública. $\mathrm{O}$ trabalho estabelece uma perspectiva crítica sobre o Programa, seguida de abordagem teórica referente a possibilidades de avaliação das políticas públicas. A análise dos dados obtidos baseia-se em duas fontes: na Pesquisa de Satisfação dos Beneficiários do Programa Minha Casa Minha Vida, realizada pelo Ministério das Cidades e pelo Ipea com beneficiários incluídos na faixa 1 (destinada ao estrato populacional com renda até 3 salários mínimos); e em entrevistas realizadas em Salvador no Residencial Jardim Cajazeiras, também destinado à faixa 1, pesquisa qualitativa desenvolvida entre 2013 e 2014. A análise problematiza as percepções dos beneficiários em relação aos resultados efetivos da política pública, tendo em vista o atendimento de expectativas e demandas associadas ao benefício. Tal perspectiva de estudo mostrou-se como uma possibilidade transdisciplinar e profícua de avaliação do Programa.
\end{abstract}

Palavras-Chave: Políticas Públicas - Pobreza Urbana - Programa Minha Casa Minha Vida.
This article aims to analyze the recipients' perceptions on the "Minha Casa Minha Vida" Program and the effectiveness of this public policy. The work establishes a critical perspective on the program, followed by a theoretical approach regarding the evaluation possibilities of public policies. The data analysis is based on two sources: the Beneficiary Satisfaction Survey conducted by the Ministry of Cities and the IPEA with beneficiaries of the "Minha Casa Minha Vida" included in the range 1 (intended for the population of women with income up to three minimum wages); and on interviews with representatives of the same group conducted in Salvador Residential Cajazeiras Garden, a qualitative research carried out between 2013 and 2014. The analysis problematizes the beneficiaries' perceptions regarding the actual results of this public policy, taking into account the fulfillment of expectations and demands associated with the benefit. Such perspective of study proved to be a transdisciplinary and productive possibility of evaluating the Program.

Keywords: Public Policies - Urban Poverty - Programa Minha Casa Minha Vida.

\section{Introdução}

O Programa Minha Casa Minha Vida representa uma realidade relativamente nova, diretamente relacionada a transformações contemporâneas do espaço urbano. Para este trabalho realizamos uma avaliação "ex post" (ou retrospectiva) do Programa, problematizando as percepções dos beneficiários em relação aos resultados efetivos da política pública. 
Assim, o presente artigo inicia-se com uma breve discussão sobre o Programa Minha Casa Minha Vida, seguida de abordagem teórica sobre diferentes perspectivas de avaliação das políticas públicas. Posteriormente, a análise dos dados obtidos baseia-se em duas fontes: a Pesquisa de Satisfação dos Beneficiários do Programa Minha Casa Minha Vida, realizada em parceria pelo Ministério das Cidades e pelo Instituto de Pesquisa Econômica Aplicada (Ipea) com beneficiários pertencentes à primeira etapa do Programa e incluídos na faixa 1 (destinada ao estrato populacional com renda até 3 salários mínimos); e entrevistas realizadas em Salvador no Residencial Jardim Cajazeiras, também destinado à faixa de 0 a 3 salários mínimos, pesquisa de cunho qualitativo desenvolvida entre 2013 e 2014. A análise dos dados questiona, dessa forma, o atendimento de expectativas e demandas associadas ao benefício, tendo em vista a unidade habitacional, a percepção de bem-estar e o acesso à rede urbana.

\section{Considerações sobre o Programa Minha Casa Minha Vida}

O Programa Minha Casa Minha Vida - PMCMV foi instituído através da Lei n. 11.977, em 7 de julho de 2009, visando "criar mecanismos de incentivo à produção e aquisição de novas unidades habitacionais ou requalificação de imóveis urbanos e produção ou reforma de habitações rurais" (BRASIL, 2009). Destaca-se que a restrição das políticas ligadas ao Fundo Nacional de Habitação de Interesse Social a ações de urbanização de assentamentos precários terminou por consolidar o PMCMV como a principal política pública de provisão de moradias no país. Segundo Shinbo (2010, p.92), a formalização do pacto habitacional do PMCMV “formalizou o 'espírito' já corrente, desde meados dos anos 1990, de incentivo à provisão privada de habitação, por meio das medidas regulatórias e do aumento de recursos destinados ao financiamento habitacional".

Em contraste ao Programa de Arrendamento Residencial (PAR) do Governo Fernando Henrique Cardoso (por meio do qual as famílias pagavam em média prestações de $\mathrm{R} \$ 132,00$ durante 15 anos, o que restringia o alcance da política pública à classe média ascendente), o PMCMV incluiu a faixa de baixa renda na alocação de recursos e provisão de moradias, ampliando o benefício aos estratos populares. No entanto, a questão fundiária persiste como problema estruturante das políticas urbanas (MARICATO, 2011), tendo em vista a notória má localização dos conjuntos habitacionais como resultado da busca do empresariado por terras baratas ou sujeitas à valorização imobiliária.

Ressalta-se que o Programa é composto por subprogramas (Programa Nacional de Habitação Urbana, Programa Nacional de Habitação Rural, MCMV 
Entidades), além de estar segmentado em estratos diferenciados de renda ( 0 a 3 salários mínimos; 4 a 6 salários mínimos; e 7 a 10 salários mínimos). Como Cardoso e Aragão (2013, p. 37) apontam, a execução do PMCMV para o estrato inferior do Programa se dá através do Fundo de Arrendamento Residencial, "cuja produção é por oferta, na qual a construtora define o terreno e o projeto, aprova-o junto aos órgãos competentes e vende integralmente o que produzir para a CAIXA". Os municípios ficam com a responsabilidade de cadastrar as famílias com rendimento de 0 a 3 salários mínimos, elaborando uma lista de demandas e apresentando-a junto à Caixa Econômica Federal. A prestação mensal para as famílias é atualmente de $\mathrm{R} \$ 25,00$, sendo que o imóvel do beneficiário é posto como garantia ao pagamento do financiamento feito pela CEF. Já para as faixas de 3 a 10 salários mínimos o financiamento ocorre através do Fundo de Garantia por Tempo de Serviço (FGTS), pelo qual as construtoras apresentam projetos de empreendimentos à Caixa, que pré-avalia e autoriza a comercialização. A comercialização, então, é feita pelos "feirões" da Caixa, podendo os pretendentes à aquisição conseguir carta de crédito na CEF para adquirir uma moradia no mercado (CARDOSO, ARAGÃO, 2013).

Vale destacar, para este ponto, que a distinção das faixas de renda não se mostra apenas como um fator de organização institucional. Para Cardoso e Aragão (2013, p.49), "existe uma forte tendência à concentração dos empreendimentos na faixa de 0 a 3 salários mínimos nas periferias", fruto do protagonismo do setor empresarial na elaboração dos projetos, que ao considerar o valor teto das unidades habitacionais (diferenciado para cada estrato de renda) busca terras mais baratas e sem infraestrutura, maximizando o lucro final. Como exemplo, aponta-se que os empreendimentos do PMCMV destinados à faixa de renda de 0 a 3 salários mínimos no Rio de Janeiro se concentraram na zona oeste da cidade, região mais precária em infraestrutura e deslocada da malha urbana (CARDOSO et al, 2013).

Assim, como aponta Shinbo (2010), a valorização do espaço urbano realizado pelas empreiteiras serve como qualificação das áreas da cidade a partir de seu público-alvo, a classe média ou a classe C. Além disso, o próprio desenho arquitetônico da unidade habitacional se modifica a partir do estrato de renda ao qual ela está direcionada, sendo que para os empreendimentos "econômicos" o princípio norteador dos projetos é a taxa de ocupação máxima, em detrimento de espaços livres, de lazer e de circulação (SHINBO, 2010). E ainda, o protagonismo empresarial impactou diretamente no desenho institucional da divisão dos estratos de renda dos beneficiários, sendo que, como aponta Maricato, o PMCMV 
[...] ouviu especialmente os empresários de construção e parte da contradição que apresenta, como a inclusão das faixas de renda situadas entre 7 e 10 salários mínimos, derivam desse fato. O mercado imobiliário privado produz no Brasil, um sproduto de luxo> acessível apenas a menos de $20 \%$ da população [...] A classe média, excluída do mercado, foi incluída no pacote (MARICATO, 2009, s/n).

Prosseguindo, Mercês (2013) traça uma importante discussão sobre a relação entre os empreendimentos do PMCMV, a doação de terras pelo Estado e os estratos inferiores de renda do Programa. Segundo a autora, a partir de trabalho empírico em Belém, a localização dos conjuntos se mostra como resultado da busca por terras baratas e pela contiguidade com terras passíveis de serem investidas. Se, por um lado, a localização dos empreendimentos para os estratos mais altos é explicado diretamente pelo preço da terra, os empreendimentos para a faixa de 0 a 3 salários mínimos exigem maior complexificação. Dessa forma, os agentes empresariais podem optar, na escolha do terreno, por terras não tão baratas, mas que resultem em retorno de lucro através do aumento do preço de terras próximas aos conjuntos. De fato, como nos mostra Maricato (2011), um dos principais resultados do PMCMV foi o aumento notável do preço de terras da periferia de São Paulo e Rio de Janeiro, chegando por vezes a dobrar de valor.

No estudo sobre a Companhia Municipal de Habitação na Região Metropolitana de Belém, Mercês (2013) aponta que a doação de terras pelo Estado pode resultar na existência de novos fatores sobre a escolha do terreno, representando a possibilidade da construção de conjuntos inseridos na malha urbana a partir do interesse do Estado na visibilidade pública e de resolvimento de conflitos fundiários. Como pode ser percebido na instituição do PMCMV, a cessão de terras pelo Estado mostra-se como critério de prioridade para contemplação dos empreendimentos (BRASIL, 2009).

À guisa de conclusão, argumenta-se que o PMCMV possuiu como direcionamento a ampliação do mercado para o atendimento da demanda habitacional de baixa renda, sendo apresentado como uma das principais ações do governo em reação à crise econômica internacional (SHINBO, 2010). Como destaca Shinbo (2010), a implementação do Programa representou um conjunto de medidas de estímulo à produção habitacional centradas no desenvolvimento dos setores imobiliários e da construção civil, através das quais a rentabilidade dos investimentos baseia-se na garantia pelo Estado de demanda para o consumo das unidades habitacionais. No contexto da crise econômica, a criação de empregos no setor da construção, o crescimento da demanda por materiais de infraestrutura e a provisão de moradias inse- 
rem o PMCMV em uma intersecção de imperativos econômicos e sociais (SHINBO, 2010).

Contudo, argumenta Maricato (2011), se por um lado o Programa expressa destacado interesse na quantidade de moradias, mostra-se alheio à fundamental condição urbana das unidades habitacionais. Os terrenos utilizados situam-se próximos a fontes de transporte, mas estariam inseridos em localizações periféricas. Segundo a autora, a Constituição Federal de 1988 e o Estatuto das Cidades representam uma base legal capaz de garantir a função social da propriedade, além de apontar a necessidade de inserção da moradia no espaço urbano. O desenho do Programa Minha Casa Minha Vida, entretanto, terminaria por reproduzir as desigualdades sociais e a segregação urbana (MARICATO, 2011).

\section{Avaliação de políticas públicas: possibilidades de análise}

As políticas públicas possuem dois aspectos fundamentais: geram um produto físico, sendo este mensurável; e geram um impacto, que pode ser tanto físico e mensurável quanto subjetivo, alterando atitudes, comportamentos e opiniões (FIGUEIREDO; FIGUEIREDO, 1986). O campo referente à análise de políticas públicas visa operacionalizar a problematização de indicadores, permitindo ao analista "compreender o problema para o qual a política pública foi desenhada, seus possíveis conflitos, a trajetória seguida e o papel dos indivíduos, grupos e instituições que estão envolvidos na decisão e que serão afetados pela política pública" (SOUZA, 2006, p. 39).

Segundo Souza (2006), a avaliação representa uma das etapas do ciclo da política pública, sendo este estruturado a partir dos processos de formação de agenda, tomada de decisão, implementação e avaliação. A avaliação de politicas públicas associa-se à discussão sobre os efeitos das decisões públicas, seus resultados e impactos, estando relacionada à atribuição de valores sobre as ações estatais. Inicialmente, como apresenta Deubel (2007), a avaliação de políticas públicas desenvolveu-se enquanto um instrumento de medição da eficácia das políticas e programas, tendo em vista o movimento de racionalização do Estado. No entanto, vê-se posteriormente uma ampliação desta perspectiva, formando-se um campo plural de concepções, métodos e enfoques, sendo que a avaliação de políticas públicas pode representar uma importante ferramenta de aprofundamento do ideal democrático. (DEUBEL, 2007).

A partir dos anos 1990 é fortalecida a perspectiva de que as pesquisas sobre políticas públicas deveriam levar em conta não somente a percepção dos técnicos e especialistas, mas também dos atores envolvidos nos diferentes processos públicos, incluindo-se aí os beneficiários. Destaca-se, então, a 
necessidade de "tener en cuenta la evaluación hecha por los actores sobre sus propias actuaciones y a partir de sus percepciones" (DEUBEL, 2007, p. 140). Por meio de Nioche (1982), Deubel argumenta a possibilidade de análise a partir da satisfação das necessidades fundamentais dos beneficiários, sendo que

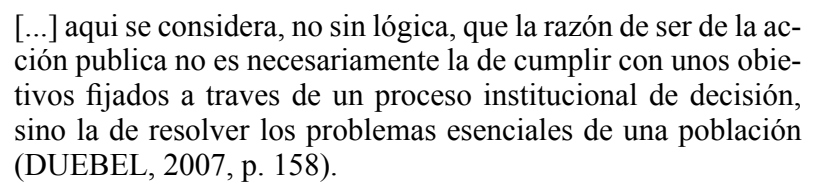

Fazendo uso de uma postura crítica em relação aos estudos sobre políticas públicas no fim da década de 1980, Marcus Faria Figueiredo e Maria Cheibub Figueiredo (1986) argumentam que grande parte de tais estudos assumia um viés comportamental e neutralista, tendo em vista a tendência de avaliação das políticas a distanciar-se da problematização do conteúdo substantivo das mesmas. Em contrapartida, os autores apontam para a necessidade de uma "avaliação política" das políticas públicas, por meio do questionamento sobre a contribuição das políticas públicas para "uma desejável quantidade e distribuição de bem-estar" (FIGUEIREDO; FIGUEIREDO, 1986, p. 108). Dessa forma, ganha corpo a possibilidade de análise da política pública a partir de seus impactos, considerando a noção de "efetividade subjetiva", que diz respeito à percepção dos beneficiários sobre transformações em sua condição social. Para isso, problematiza-se a adequação dos resultados da política pública às demandas, desejos e aspirações dos beneficiários, levando em conta os desdobramentos da noção de bem-estar social a partir de suas dimensões material, psicológica e cultural (FIGUEIREDO; FIGUEIREDO, 1986).

Com base nessa preocupação, ressaltamos que a perspectiva de estudo sobre a dimensão subjetiva de bem-estar mostra-se na América Latina como terreno fértil para estudos. Segundo a Comissão Econômica para América Latina e o Caribe - CEPAL (2013), vê-se uma necessidade eminente de estudos que analisem os aspectos subjetivos das políticas públicas e das dimensões de bem-estar. Mostra-se profícuo relacionar, assim como aponta Villatoro (2012), o bem-estar de grupos sociais a aspectos subjetivos das percepções e atitudes dos indivíduos sobre suas condições de vida e relações sociais.

Tal discussão nos leva a um questionamento fundamental: se as diferentes percepções dos beneficiários sobre os resultados da política pública estão relacionadas a expectativas que são socialmente construídas, e estando 
as demandas e expectativas relacionadas à trajetória de vida dos beneficiários, tais percepções podem ser utilizadas como indicadores para a avaliação das políticas públicas? Para dar conta dessa problemática, nos reportamos à perspectiva de que a posição que o indivíduo ocupa no espaço social, a partir da distribuição de diferentes tipos de capital, associa-se a percepções sobre o espaço e à tomada de decisões pelos atores (BOURDIEU, 2013).

Como afirma Bourdieu (2013), relacionados às condições de existência são produzidos habitus, sistemas de disposições duráveis e transponíveis, princípios geradores e organizadores de práticas e de representações que podem ser objetivamente adaptadas. Dessa forma, a percepção da experiência social (associada à estrutura do habitus) estaria relacionada às necessidades econômicas e sociais, que se manifestariam através das relações familiares da economia doméstica (BOURDIEU, 2013). Tal argumento nos permite afirmar uma vinculação entre experiências relacionadas à posição social do indivíduo e percepções sobre o mundo da vida, embora de maneira não determinística (já que são transponíveis).

Defendemos, pois, que a proposta de avaliação do Programa Minha Casa Minha Vida relacionada à percepção dos beneficiários sobre os resultados da política pública não pode estar descolada de uma compreensão sobre o mundo da vida dos entrevistados. No entanto, tal elemento não representa uma fragilização do método de avaliação da política pública, mas sim como uma possibilidade estimulante de diálogo entre saberes das ciências sociais. Mostra-se necessário questionar de que forma o acesso à política pública relaciona-se a transformações positivas e/ou negativas nas condições de vida dos beneficiários, e de que forma a problematização de suas trajetórias de vida (sendo o benefício entendido enquanto uma experiência social vivenciada pelo beneficiário a partir de seu mundo da vida) nos permite traçar linhas de análise sobre a política pública. No entanto, carece de discussão como trajetórias de extrema vulnerabilidade social no momento de pré-benefício (no caso do Programa, moradores de habitações irregulares e sujeitas a risco) condicionariam expectativas mínimas de acesso a bens e serviços, e de que forma tais expectativas poderiam produzir percepções positivas sobre o benefício pela política pública (acesso à casa própria em terreno urbanizado). Como veremos, tal elemento mostrou-se presente nas entrevistas.

Assim, a partir de indicadores quantitativos e qualitativos, problematizaremos as diferentes percepções dos beneficiários do Programa Minha Casa Minha Vida sobre os impactos da política pública em suas condições de vida, elemento fundamental para a compreensão da política pública e da vida social dos atores inseridos no espaço urbano. 


\section{Análise de dados da "pesquisa de satisfação dos beneficiários do progra- ma Minha Casa Minha Vida"}

Objetivando aferir a satisfação dos beneficiários do PMCMV em relação à política pública, o questionário aplicado pela Ipea parte do uso da escala tipo Likert, através da qual os entrevistadores propõem afirmações aos entrevistados relativas a percepções e eventos. Tais afirmações não são necessariamente verdadeiras, e "a adequação de cada afirmação com a realidade do entrevistado é observada por meio do grau de concordância ou discordância de cada um com relação às afirmações" (BRASIL, 2014, p. 27).

Assim, o questionário da Pesquisa de Satisfação dos Beneficiários do Programa Minha Casa Minha Vida foi compartimentalizado em cinco partes: a funcionalidade da unidade habitacional; o entorno da moradia; a inserção urbana; as despesas com a moradia; e a percepção de bem-estar do beneficiário (BRASIL, 2014). São propostas aos entrevistados afirmações sínteses referentes à satisfação do indivíduo e à satisfação do beneficiário sobre a "moradia atual, sua percepção de melhoria de qualidade de vida associada à obtenção da moradia e sua intenção de ficar na moradia ou mudar" (BRASIL, 2014, p. 27). Cada etapa foi dividida em diferentes tópicos, que juntos totalizam 22 questões, através das quais produziu-se uma nota média (de 0 a 10) para cada tópico referente à satisfação dos beneficiários. A amostra, representada por mais de 7 mil beneficiários incluídos na faixa 1 (destinada à população com renda entre 0 e 3 salários mínimos) abrangeu as 5 regiões do país.

Dois pontos destacam-se como relevantes para a compreensão dos dados obtidos. Em primeiro lugar, os beneficiários relataram nas entrevistas a existência de situações de risco na antiga moradia, sendo a mais frequente a de alagamento $(18,4 \%)$, seguida por proximidade de lixões e esgoto a céu aberto $(13,7 \%)$, inundações $(13,4 \%)$ e deslizamentos de encostas $(6,7 \%)$. Isso nos permite afirmar que as condições de vida dos entrevistados no momento anterior ao benefício revelam-se como de extrema vulnerabilidade social, manifesta a partir da negação dos direitos em uma situação de risco decorrente da inserção precária no espaço urbano. Em segundo lugar, os entrevistados foram questionados sobre as políticas públicas prioritárias para si e suas famílias, sendo que as seis mais importantes foram, em ordem de prioridade: Melhoria dos serviços de saúde; educação de qualidade; governo honesto e atuante; acesso a alimentos de qualidade; apoio às pessoas que não podem trabalhar; e melhores oportunidades de trabalho. Como destaca a pesquisa, "tais itens referem-se à ocupação e às necessidades básicas (incluindo serviços públicos) das famílias" (BRASIL, 2014, p. 73). 
Prosseguindo para a análise de dados propriamente dita, o trabalho aponta para médias elevadas de satisfação em relação às unidades habitacionais $(8,62$, sendo a nota máxima 10$)$. Esta etapa da pesquisa obteve maiores médias de satisfação quando comparadas aos outros quesitos, sendo que "esse fato revela que os beneficiários entrevistados têm percepções variadas com relação ao conforto das novas moradias, mas isso parece não afetar de forma decisiva sua satisfação com o fato de estar numa moradia nova e adequada" (BRASIL, 2014, p. 81). É necessário, portanto, contrastar a situação da moradia pré-benefício precária e sujeita a riscos com a percepção dos entrevistados sobre o Programa, sendo a inserção do beneficiário em bairro urbanizado entendida como fator positivo em sua vida social.

O segundo quesito, relativo ao entorno das moradias, apresentou médias bastante diversas. O tópico "vizinhança" foi o único que obteve médias consideradas elevadas $(8,61)$, em contraste aos tópicos "segurança" (média de $4,74)$, lazer $(3,49)$ e trabalho social $(3,29)$, este último evidenciando a dificuldade de acesso dos beneficiários à rede socioassistencial no momento de pós-ocupação. O trabalho aponta para a existência de uma prioridade de valores pelos beneficiários quanto aos tópicos, sendo que "a percepção de que a família se mudou de uma área de risco ou assentamento precário para um bairro urbanizado parece prevalecer sobre o reconhecimento da falta de áreas de lazer e da insegurança" (BRASIL, 2014, p. 82). No entanto, tais dados corroboram para a existência de percepções negativas dos beneficiários referentes a dimensões fundamentais de seu cotidiano.

Seguidamente, o terceiro quesito relativo à "inserção urbana" após o benefício obteve médias marcadamente negativas. Sobre o acesso aos transportes, vê-se uma disparidade entre uma média razoável quanto à facilidade de acesso a transportes públicos $(6,65)$ e uma média baixa referente à demora nos transportes no traslado à escola ou trabalho $(3,87)$. Dessa forma, a pesquisa aponta para a manifesta distância dos empreendimentos da faixa 1 do Programa dos centros urbanos, decorrente da periferização dos conjuntos habitacionais. Já em relação ao acesso a serviços públicos, vê-se avaliações negativas dos moradores sobre o acesso a serviços de saúde $(4,36)$ e escola $(4,03)$, evidenciando "certo descompasso na resposta dos governos locais e estaduais na instalação de postos de saúde, pronto atendimento, creches e escolas próximos às áreas dos empreendimentos" (BRASIL, 2014, p. 83). Contudo, novamente as notas de satisfação referentes à localização da unidade habitacional apontaram para uma média de avaliação relativamente positiva dos beneficiários $(7,81)$, elemento que expressa o impacto do processo de vulnerabilidade pré-benefício na percepção dos beneficiários sobre os resultados da política pública. Como argumenta a pesquisa, 
[...] esse fato sugere que, apesar de indicarem carências de saúde e educação, assim como demora no traslado para o trabalho e escola, os beneficiários entrevistados estão relativamente satisfeitos com a localização da moradia. Novamente, as avaliações de cunho subjetivo quanto à propriedade e à moradia digna bem constituída, em bairro urbanizado - parecem prevalecer sobre as deficiências percebidas com relação à inserção urbana (BRASIL, 2014, p. 84).

Em relação ao custo de vida, o quesito foi divido em três tópicos, relativos a despesas com transporte, contas de aluguel e contas de água, luz e condomínio. As médias referentes a despesas com transportes obteve média de avaliação baixa $(4,16)$, o que aponta para aumento das despesas dos beneficiários após o acesso à unidade habitacional. Em contrapartida, a avaliação quanto às despesas com aluguel apontaram para uma média de satisfação elevada $(7,93)$, contrastada por médias baixas de avaliação quanto a despesas com água, luz e condomínio $(4,29)$. Estima-se que as despesas com água, luz e condomínio comprometiam $11,3 \%$ da renda dos beneficiários entrevistados, sendo a avaliação negativa dos beneficiários também decorrente do fato de que as famílias da Faixa I do Programa "vieram, em sua maior parte, de moradias em assentamentos precários e áreas de risco - locais onde a água e a energia elétrica são consumidas sem custo privado e tampouco há organização condominial" (BRASIL, 2014, p. 85).

Por fim, a pesquisa questionou os entrevistados sobre a percepção de bem -estar no momento de pós-ocupação, a partir da satisfação geral com a nova moradia, a melhoria de vida (aumento de bem-estar) e a intenção de permanecer na unidade habitacional. Os três tópicos apresentaram notas bastante elevadas, com médias de 8,77 para a satisfação geral com a nova moradia; 8,62 para a percepção de aumento de bem-estar, relacionado à melhoria das condições de vida; e média de 9,44 apontando para a resposta negativa dos beneficiários sobre o desejo de se mudarem da unidade habitacional.

A partir desse quadro de análise, a pesquisa conclui que

[...] o elevado grau de satisfação não implica uma aceitação total e sem indicações de pontos críticos do PMCMV. O conjunto das respostas, ao contrário, indica uma melhora geral das condições de vida dos beneficiários, mesmo considerando que o conforto da moradia não seja o ideal, que o entorno e a localização dos empreendimentos tenham inadequações e que o custo de vida com despesas ligadas ao domicílio (exceto aluguel) tenha crescido. Esses pontos verificados no campo trazem subsídios para aprimorar os projetos desses empreendimentos e a própria política de subsídios do PMCMV em suas fases futuras (BRASIL, 2014, p. 87). 
Vale destacar que outro elemento apontado pela pesquisa se mostra frutífero para o nosso trabalho, sendo ele a interlocução entre moradores e poder público após o benefício. Segundo a pesquisa, mesmo sendo um dos "alicerces de planejamento das políticas públicas", a interlocução entre sociedade civil e Estado mostrou-se pouco frequente, limitando-se a visitas de assistentes sociais do CRAS (Centro de Referência da Assistência Social) e de equipes sociais da Caixa Econômica Federal (BRASIL, 2014). Tal fator representa, assim, um obstáculo para o encaminhamento de demandas dos beneficiários ao poder público.

A seguir, analisaremos dados referentes à pesquisa qualitativa realizada em Salvador, o que nos permitirá traçar possíveis diálogos com o trabalho realizado pelo Ipea e pelo Ministério das Cidades. A partir daí, esperamos estabelecer considerações mais aprofundadas sobre o tema.

\section{Percepções dos beneficiários do Residencial Jardim Cajazeiras, Salvador/BA}

O Residencial Jardim Cajazeiras está localizado no bairro Jardim Cajazeiras, Salvador, BA, e foi disponibilizado no dia 31 de outubro de 2011 para o estrato populacional entre 0 e 3 salários mínimos, estando situado na modalidade de doação de terras pelo Estado. Foram entregues para este condomínio 200 unidades habitacionais pelo Programa Minha Casa Minha Vida, organizadas em 10 blocos, com 20 apartamentos em cada, sendo que os apartamentos dispõem de 43 metros quadrados.

Como Carvalho e Pereira (2008) argumentam, nos anos 1980 um conjunto de intervenções na capital baiana terminaram por configurar de maneira decisiva "um novo padrão de produção do espaço urbano, com a configuração de três vetores bem diferenciados de expansão da cidade: a Orla Marítima norte, o 'Miolo' e o Subúrbio Ferroviário" (CARVALHO; PEREIRA, 2008, p. 85), tendo em vista um padrão extremamente desigual de desenvolvimento urbano, marcado pela segregação socioespacial com base na periferização da pobreza. O Conjunto Residencial Jardim Cajazeiras, objeto de nosso trabalho, localiza-se no segundo vetor referido pelos autores, o Miolo da cidade de Salvador,

[...] localizado no centro geográfico do município, [que] começou a ser ocupado pela implantação de conjuntos residenciais para a "classe média baixa" na fase áurea da produção imobiliária através do Sistema Financeiro de Habitação, tendo a sua expansão continuada por loteamentos populares e sucessivas invasões coletivas, com uma disponibilidade de equipamentos e serviços bastante restrita (CARVALHO; PEREIRA, 2008, p. 86). 
Após essa breve contextualização sobre o conjunto habitacional, passemos à metodologia de pesquisa. Foram realizadas para esta etapa entrevistas semiestruturadas, em quantidades variadas, com 8 moradores do referido conjunto habitacional. Parte-se da perspectiva de que a pesquisa qualitativa "fornece os dados básicos para o desenvolvimento e compreensão das relações entre os atores sociais e sua situação" (GASKELL, 2013, p. 65), sendo que os beneficiários representam a unidade de referência para o trabalho. Assim, esta etapa da pesquisa problematiza os chamados dados subjetivos, relacionados à interpretação e compreensão da realidade social pelo ator entrevistado (MINAYO, 2012). Privilegiam-se nas entrevistas perguntas relacionadas à percepção dos beneficiários sobre a qualidade de vida e bem-estar social, assim como o acesso a bens e serviços por meio das características de inserção urbana da unidade habitacional.

Em geral, os entrevistados avaliam como positivas as mudanças das condições de moradia após o benefício pelo Programa, já que tais mudanças são apresentadas como potencializadoras de melhorias na qualidade de vida dos moradores. A precariedade da antiga moradia é confrontada com as condições atuais pós-benefício, assim como apontam as interlocutoras 1 e 2 :

De bom, no Minha Casa Minha Vida? Bom, só em eu estar aqui, debaixo desse teto maravilhoso, já é uma grande coisa [Interlocutora 1].

Eu vim da ocupação Gal Costa, Sussuarana, eu vim para aqui, pro condomínio, só que nós temos uma melhoria... qual é a melhoria? São as moradias. Porque lá eu morava em um barraco, entendeu? [Interlocutora 2].

De forma semelhante, os Interlocutores 3, 4 e 5 relacionam o benefício à superação de problemas anteriores da antiga moradia. Ganha importância na fala dos entrevistados a associação da antiga moradia às noções de risco, insalubridade e instabilidade, que são evocadas para comparar a atual moradia pelo Programa e a antiga habitação.

$100 \%$ (melhoria da atual moradia em relação à antiga). Eu vivia lá com ratos, com esgoto a céu aberto, totalmente diferente. Para mim né, totalmente diferente [Interlocutor 3].

Porque antes eu morava em barraco de tábua, numa favela, poderia dormir e não acordar, entendeu, devido à moradia mesmo, da maneira que a gente vivia, e hoje graças a Deus, moro dentro de uma casa, tranquilo, toda gradeada, com segurança dos próprios moradores vizinhos, então foi um impacto positivo [Interlocutor 4]. 
Porque eu vivia na lama né. Era de tábua... logo no começo era de tábua, depois eu construí. Mas mesmo assim, não mudou nada né. Quando chovia, molhava tudo, alagava a casa, perdia os móveis tudo [Interlocutora 5].

Tais elementos corroboram a argumentação de Holston (2013), a partir da perspectiva da discussão sobre a cidadania diferenciada no Brasil, sobre o estatuto legal da moradia como elemento condicionante do acesso a direitos sociais. É recorrente na fala dos beneficiários a percepção da moradia como elemento chave em um processo de vulnerabilidade mais amplo, onde a substancial melhoria da habitação resultou em uma transformação positiva na inserção do morador em uma estrutura social marcadamente instável. Podemos trazer, como exemplo, as falas dos interlocutores 6 e 7 :

Eu acho que aqui, graças a Deus, aonde eu tava morando, pra onde eu tô hoje, aqui eu estou no paraíso. Eu não vou mentir, eu falo pra qualquer um: eu morava em uma favela, não vou mentir, num barraquinho de madeira. Hoje eu estou aqui, eu estou dando graças a Deus [Interlocutor 6].

Eu morava na Avenida Gal Costa, em uma ocupação de área federal, que era uma área do DENOCS que nós ocupamos mais de 4 anos. E de lá viemos para aqui, lá morava em barraco de tábua, não tinha saneamento básico, não tinha rede de esgoto, não tinha água encanada, não tinha energia... não tinha o básico para você ter uma vida saudável, lá não tinha. Embora você era discriminado, né, "ah, mora na favela, mora num barraco", e hoje não, a pessoa que está aqui tem um status de vida melhor do que o que tinha lá no Gal Costa [Interlocutora 7].

Dessa forma, destacamos dois pontos fundamentais: a) a melhoria das condições de moradia através do benefício pelo Minha Casa Minha Vida representa, na percepção dos beneficiários, a passagem de uma realidade marcada pela ausência de segurança, de serviços básicos e de bem-estar com relação à moradia para uma realidade mais segura e com estabilidade material; b) além disso, a transformação material representou também uma melhoria significativa na autoestima dos moradores, através do reconhecimento da moradia regularizada pós-benefício como elemento positivo de cidadania e de status. Tal fator merece destaque, visto o caso brasileiro marcado pela diferenciação e estratificação da população no que diz respeito ao acesso a direitos, estando a condição material e legal da moradia presente como elemento condicionante.

A partir desses exemplos, constatamos que a efetividade subjetiva do Programa Minha Casa Minha Vida apresenta elementos relacionados a percepções positivas dos moradores sobre as novas condições de moradia. No 
entanto, a avaliação sobre a moradia não é a única balizadora da percepção de efetividade da política pública. Argumentamos que o benefício pela política pública e a transformação da situação de vulnerabilidade do morador transformam também um conjunto de valores que orientam as expectativas quanto ao acesso a bens e serviços, assim como apontado por Santos (2013). A pobreza estaria expressa, tendo como foco de análise o pobre, a partir de um padrão de valores e condições materiais, sendo que o indivíduo é definido enquanto pobre a partir de sua situação específica em uma determinada sociedade. Dessa forma, o acesso a bens e serviços através de políticas públicas terminaria por reorientar as expectativas dos beneficiários, agora inscritos em outra dimensão material e valorativa (SANTOS, 2013). A pobreza, dessa forma, deve ser entendida como situacional (porque diz respeito a uma situação social, e não a generalidades adscritas) e relacional (porque diz respeito ao indivíduo enquanto relacionado à sociedade e ao contexto urbano).

Assim, vemos que o benefício pela política pública expandiu a noção de direitos dos beneficiários, já que, como vimos, a transformação de condições materiais resultou em uma ampliação das expectativas do acesso do indivíduo à rede urbana. Os beneficiários que relatam o contexto pré-benefício como marcado pela insegurança, negação de direitos e precariedade, agora exprimem a necessidade do atendimento das demandas urbanas locais, fator que vai ter espaço privilegiado na produção de percepções de efetividade da política pública pelos moradores. Dessa forma, a precariedade dos serviços de saúde, educação e lazer próximos ao conjunto habitacional são fatores que impactam negativamente na percepção de efetividade da política pública. Vejamos alguns diálogos:

O que falta aqui é o posto de saúde. O posto de saúde e uma lotérica. Tem que sair daqui e ir pra Pau da Lima... [Interlocutor 6].

Porque estudo, educação, saúde, segurança, muito longe. Geralmente os colégios quase que não estão, como é que se diz, usando né, arcando com as funções deles, adequadas né, está tudo fora do padrão. Colégios, saúde, não está bem [Interlocutora 1].

Está precário, está precário, muito precário (serviços de educação, saúde e lazer na atual moradia) Porque não tem, aqui mesmo no condomínio tem uma quadra de esporte pra 200 famílias. Que lazer as crianças vão ter? Não tem. (sobre a escola) Precária também, não tem escola no bairro, pra demanda do condomínio, as crianças do condomínio tem que sair daqui pra ir pra outro bairro pra estudar. (saúde) Não tem também, tem que ir pra outro bairro procurar, no bairro também não tem serviço de saúde [Interlocutor 4] 
A educação aqui é longe né. Quando vai no posto nunca tem nada, nunca tem remédio, médico, só pra quem é da casa. Aqui é ruim. Escola é precária viu. Aqui é muito longe [Interlocutora 5].

Em verdade, o que vimos é que direitos universais se tornaram expectativas, através das quais exige-se que as transformações das condições de moradia sejam acompanhadas pela melhoria dos serviços de infraestrutura urbana na localidade atual. Além disso, como apresenta Holston (2013), o processo de democratização ampliou a possibilidade de disputa pelos direitos, através do embasamento constitucional a reivindicações dos movimentos de moradia. A democracia é vista, então, como uma arena pública de disputa por expectativas não atendidas no contexto de democracia disjuntiva brasileira (HOLSTON, 2013), marcada pela conflitualidade entre desigualdade social extrema e disputa por direitos. As falas dos interlocutores 7 e 8 trazem elementos significativos para tal discussão, na medida em que apresentam o benefício enquanto elemento não garantidor do acesso aos direitos sociais estabelecidos pela Constituição de 1988 .

\footnotetext{
Não existe você fazer um projeto pela metade. Quando o Governo programa isso ele tem que programar que venha, porque se vem habitação, porque no artigo VI da Constituição, você quer o quê? Moradia digna. Mas o artigo VI não diz só moradia digna. É saúde, é educação... e aqui, pelo menos nesse projeto não existe isso. Não tem escola para os nossos filhos, não tem creche, não tem área de lazer, não tem posto de saúde, então, incompleto [Interlocutora 7].

Mas a dificuldade é, que a gente morava dentro das ocupações, e a gente sempre lutou para ter a casa, tá no artigo VI da Constituição que todo cidadão tem direito à moradia. Então o Governo, ele tem por obrigação de manter esse artigo, cumprir a lei. Cumprir a lei de que forma, a pessoa tem que ter o direito à moradia, e o direito à moradia pra mim é você não pagar. Se tá no artigo que o Governo tem que, se eu não tenho condições de ter, o Governo tem que arcar [Interlocutor 8].
}

A percepção de efetividade em relação ao Programa Minha Casa Minha Vida insere-se, então, em um terreno conflituoso. Nesse campo de percepções sobre os direitos, vemos a relação estabelecida pelos entrevistados entre melhorias das condições de moradia, potencializadoras do deslocamento do indivíduo em direção a espaços mais consolidados no processo de vulnerabilidade; e expectativas não atendidas de melhorias de serviços públicos, a partir da percepção negativa sobre as condições da infraestrutura urbana no novo local de moradia. 
Tal problemática mostra-se recorrente nos conjuntos habitacionais do Programa Minha Casa Minha Vida, através da periferização dos condomínios destinados à população situada na faixa de 0 a 3 salários mínimos, assim como destacamos no desenvolvimento deste trabalho. Dessa forma, o problema apresentado por Carvalho e Pereira (2008), sobre a contiguidade entre categorias ocupacionais e infraestrutura urbana, termina por ser reproduzido no próprio desenho e implementação do Programa. O padrão centro-periferia de desenvolvimento urbano das metrópoles brasileiras apresenta-se, pois, como elemento fundamental para compreendermos o desigual acesso ao direito à cidade pelos beneficiários. No entanto, nos parece profícuo a avaliação de que não devem ser estabelecidas generalizações sobre a localização dos empreendimentos, sendo necessário questionar elementos que complexifiquem tal fator, como "a capacidade institucional dos municípios de planejar não apenas os serviços ligados ao PMCMV, mas os que envolvem a cidade como um todo" (BRASIL, 2014, p. 94).

\section{Considerações finais}

Após este percurso de análise, argumentamos que a problematização dos dados apresentados corrobora com a argumentação de Esping-Andersen (1990) sobre a necessidade de problematizar a política social enquanto uma força ativa no ordenamento das relações sociais, levando em conta diferentes processos de estratificação. Tais processos, como buscamos demonstrar, são fundamentais para a análise das políticas públicas.

Ao cruzarmos os dados quantitativos e qualitativos das pesquisas apresentadas, destacam-se alguns elementos essenciais para compreensão das percepções dos beneficiários sobre os resultados do Programa Minha Casa Minha Vida. Primeiramente, vê-se uma dualidade existente entre a percepção sobre a unidade habitacional e a percepção do acesso aos bens e serviços urbanos pelos beneficiários. Dessa forma, os beneficiários apresentam avaliações extremamente positivas sobre as características da unidade habitacional, tendo em vista discursos que contrastam a atual moradia pelo Programa à antiga moradia sujeita a riscos. Como apresenta a pesquisa quantitativa realizada pelo Ipea e pelo Ministério das Cidades, percebe-se que os distintos fatores trabalhados no questionário apresentam pesos diferentes para a satisfação dos beneficiários, sendo a inserção da unidade habitacional em terreno urbanizado elemento preponderante. $\mathrm{Ou}$, como disse um dos moradores entrevistados em Salvador, o Programa seria positivo para a melhoria de suas condições de vida, porque "a pessoa que está aqui tem um status de vida melhor do que o que tinha lá no Gal Costa". 
No entanto, o benefício está associado a uma reorientação de expectativas dos beneficiários no que diz respeito ao acesso a bens e serviços urbanos. Como bem destacam o Ipea e o Ministério das Cidades, a avaliação negativa dos beneficiários sobre os serviços de saúde e educação, assim como do traslado até os centros urbanos, não está relacionada à oferta de políticas públicas no período anterior ao benefício. Mas sim ao fato de que os beneficiários expressam após o acesso ao Programa a expectativa de que as melhorias experienciadas nas unidades habitacionais sejam acompanhadas pela inserção em redes de serviços urbanos (BRASIL, 2014). Retomando um dos beneficiários entrevistados em Salvador, vemos a percepção de que o Programa Minha Casa Minha Vida seria "incompleto", já que provê moradia digna mas não contempla as obrigações de um Estado democrático estabelecidas no artigo VI da Constituição.

Argumentamos, pois, que a avaliação do Programa Minha Casa Minha Vida a partir das percepções dos beneficiários sobre os resultados da política pública aponta para elementos positivos e negativos de efetividade. Merece destaque o fato de que os elementos negativos (acesso a bens e serviços urbanos após o benefício) não devem ser entendidos como efeitos secundários do Programa, mas sim decorrentes da baixa capacidade estatal em prover moradias em áreas centrais (transferindo grande parte das atribuições à iniciativa privada) e de intervir nos conflitos urbanos, especialmente de ordem fundiária, sendo que o PMCMV ignora, de maneira substancial, o vínculo entre política habitacional e política fundiária ou urbana (MARICATO, 2011). Como discutido, tal elemento soma-se à ineficácia da resposta dos governos locais e estaduais na implementação de serviços de saúde e educação nas áreas próximas aos conjuntos habitacionais (BRASIL, 2014).

Em relação a elementos que corroboram com percepções positivas de efetividade da política pública, destaca-se a inclusão da faixa de 0 a 3 salários mínimos no acesso às unidades habitacionais, sendo que a moradia ofertada pelo Programa é percebida pelos beneficiários como elemento garantidor de maior qualidade de vida. Como problematizado pelas pesquisas, tais percepções estão associadas a privações dos beneficiários no momento anterior ao benefício, sujeitos a situações de risco relacionadas à inserção precária no espaço urbano. No entanto, vale ressaltar que a oferta de unidades habitacionais à faixa inicial do Programa está relacionada à garantia pelo Estado de demanda constante para as empresas contratadas, da mesma forma que expressa um processo de segmentação da política pública. Tal segmentação, como vimos a partir da periferização dos conjuntos habitacionais destinados à faixa de $0 \mathrm{a}$ 3 salários mínimos, estabelece-se com base na estratificação socioeconômica dos beneficiários, (CARDOSO; ARAGÃO, 2013) e a qualificação das áreas 
da cidade a partir do público-alvo, por meio da valorização seletiva do espaço urbano (SHINBO, 2010).

Os elementos acima discutidos são apreendidos e ressignificados pelos movimentos sociais urbanos, em intersecção com o Estado, disputando a vinculação do Programa ao Sistema Nacional de Habitação de Interesse Social, como propõe a Federação Nacional dos Arquitetos e Urbanistas; a aproximação do Programa à política de desenvolvimento urbano submetida ao Estatuto das Cidades, como proposto na 4.a Conferência Nacional das Cidades; e o incentivo à construção de unidades habitacionais em áreas centrais, bem como a submissão do Programa ao Plano Diretor de cada município e a garantia de 10\% dos empreendimentos para o Minha Casa Minha Vida Entidades, como defendido por diversos movimentos sociais em carta proposta apresentada ao Ministério das Cidades em 2014.

Podemos perceber, pois, que a avaliação do PMCMV por meio da percepção dos beneficiários, tendo em vista a utilização de dados quantitativos e qualitativos, permite problematizações profícuas sobre o tema, levando a considerações sobre o Programa e a questionamentos metodológicos sobre o estudo de políticas públicas. Da mesma forma, dialoga com novas possibilidades de estudo sobre as trajetórias de vida dos beneficiários, sendo a percepção sobre os resultados da política pública de fundamental importância para a compreensão sobre o processo de vulnerabilidade vivenciado no cotidiano pelos atores sociais inseridos, sob diferentes condições, no espaço urbano.

\section{Referências}

BOURDIEU, Pierre. O Senso Prático. Petrópolis, RJ: Vozes, 2013. 472 p.

BRASIL. (Presidência da Casa Civil). Lei n. 9.887, de 7 de julho de 2009. Dispõe sobre o Programa Minha Casa, Minha Vida - PMCMV e a regularização fundiária de assentamentos localizados em áreas urbanas; altera o Decreto-Lei no 3.365, de 21 de junho de 1941, as Leis nos 4.380, de 21 de agosto de 1964, 6.015, de 31 de dezembro de 1973, 8.036, de 11 de maio de 1990, e 10.257, de 10 de julho de 2001, e a Medida Provisória no 2.197-43, de 24 de agosto de 2001; e dá outras providências. Brasília, DF, 7 julho. 2009. Disponível em: http://www.cidades. gov.br/images/stories/ArquivosSNH/ArquivosPDF/Leis/L11977compilado 200907 07.pdf Acesso em: 28 jan. 2015

BRASIL. (Ministério das Cidades/Secretaria de Assuntos Estratégicos da Presidência da República.) Pesquisa de satisfação dos beneficiários do Programa Minha Casa Minha Vida. Brasília, DF: MCIDADES; SNH; SAE-PR; IPEA, 2014.

CARDOSO, Adauto Lúcio; ARAGÃO, Thêmis Amorim. Do fim do BNH ao Programa Minha Casa Minha Vida: 25 anos da política habitacional no Brasil. In: CARDOSO, Adauto Lúcio (Org.) O Programa Minha Casa Minha Vida e seus Efeitos Territoriais. Rio de Janeiro: Letra Capital, 2013. p. 17-66. 
CARDOSO, Adauto Lúcio et al. Minha Casa Minha Sina: implicações da recente produção habitacional pelo setor privado na Zone Oeste da cidade do Rio de Janeiro. In: CARDOSO, Adauto Lúcio (Org.), O Programa Minha Casa Minha Vida e seus efeitos territoriais. Rio de Janeiro: Letra Capital, 2013. p. 143-160.

CARVALHO, Inaiá Maria Moreira de; PEREIRA, Gilberto Corso. As Cidades de Salvador. In: CARVALHO, Inaiá Maria Moreira de; PEREIRA, Gilberto Corso (Org.), Como anda Salvador e sua Região Metropolitana. Salvador: Edufba, 2008, p. 81-108.

CEPAL. Panorama Social da América Latina 2013. Santiago, Chile: Naciones Unidas - CEPAL, 2013. (Coleción Informes Anuales).

DEUBEL, André-Nöel Roth. Politicas Públicas: Formulación, Implementación y Evaluación, Bogotá: Aurora, 2007. 166 p.

FIGUEIREDO, Marcus Faria; FIGUEIREDO, Argelina Maria Cheibub. Avaliação política e avaliação de políticas: um quadro de referência teórica. Análise e Conjuntura, Belo Horizonte, 1 (3), p. 107-127, set./dez. 1986.

HOLSTON, James. Cidadania Insurgente: disjunções da democracia e da modernidade no Brasil. São Paulo: Companhia das Letras, 2013, 485p.

MARICATO, Ermínia. O impasse da política urbana no Brasil. Petrópolis: Editora Vozes, 2011. 219 p.

. O "Minha Casa" é um avanço, mas segregação urbana fica intocada. Carta Maior, Política. 27/05/2009. Disponível em: http://cartamaior.com.br/?/Editoria/Politica/O-Minha-Casa-e -um-avanco-mas-segregacao-urbana-fica-intocada/4/15160 Acesso em 05/01/2015

MERCÊS, Simaia. Programa Minha Casa Minha Vida na Região Metropolitana de Belém: localização dos empreendimentos e seus determinantes. In: CARDOSO, Adauto Lúcio (org), O Programa Minha Casa Minha Vida e seus Efeitos Territoriais. Rio de Janeiro: Letra Capital, 2013. p.187-204.

NIOCHE, Jean Pierre. De l'évaluation à l'analyse des politiques publiques. Revue Française de Science Politique, [S.1.], vol. 32, n. 1, p. 32-61, fev. 1982.

SANTOS, Milton. Pobreza Urbana. 3 ed., São Paulo: Edusp , 2013, 136 p.

SHINBO, Lúcia Zanin. Habitação social, habitação de mercado: a confluência entre Estado, empresas construtoras e capital financeiro. 2010, 359 p. Tese (Doutorado do Programa de Pós-Graduação em Arquitetura e Urbanismo e Área de Concentração em Teoria e História da Arquitetura e do Urbanismo). Escola de Engenharia de São Carlos da Universidade de São Paulo, São Carlos, 2010.

SOUZA, Celina. Políticas públicas: uma revisão de literatura. Sociologias, Porto Alegre, ano 8, n. 16, p. 20-45, jul./dez 2006.

VILLATORO, P. La medición del bienestar a través de indicadores subjetivos: una revisión. Serie Estudios Estadísticos y Prospectivos, n 79 , Santiago de Chile: Comisión Económica para América Latina y el Caribe, 2012. 
Submissão em: 10/02/2015

Revisão em: 15/04/2015

Aceite em: 27/04/2015

Vitor Matheus Oliveira de Menezes é mestrando do Programa de Pós-Graduação em Ciências Sociais pela Universidade Federal da Bahia; Bacharel em Sociologia pela mesma Instituição. Bolsista do CNPq. Endereço para correspondência: Faculdade de Filosofia e Ciências Humanas - UFBA - Estrada de São Lázaro, 197. Federação, CEP: 40.210-730 .Salvador,BA, Brasil. E-mail: vitormatheus_ba@hotmail.com 